\title{
Influence of Parent-Child Communication Styles on Social Anxiety: Observation During a Film Discussion Task
}

Jonathan M. Ortega

West Virginia University

Follow this and additional works at: https://researchrepository.wvu.edu/etd

\section{Recommended Citation}

Ortega, Jonathan M., "Influence of Parent-Child Communication Styles on Social Anxiety: Observation During a Film Discussion Task" (2012). Graduate Theses, Dissertations, and Problem Reports. 3528. https://researchrepository.wvu.edu/etd/3528

This Thesis is protected by copyright and/or related rights. It has been brought to you by the The Research Repository @ WVU with permission from the rights-holder(s). You are free to use this Thesis in any way that is permitted by the copyright and related rights legislation that applies to your use. For other uses you must obtain permission from the rights-holder(s) directly, unless additional rights are indicated by a Creative Commons license in the record and/ or on the work itself. This Thesis has been accepted for inclusion in WVU Graduate Theses, Dissertations, and Problem Reports collection by an authorized administrator of The Research Repository @ WVU. For more information, please contact researchrepository@mail.wvu.edu. 
Influence of Parent-Child Communication Styles on Social Anxiety:

Observation During a Film Discussion Task

\author{
Jonathan M. Ortega
}

Thesis defense submitted to the Eberly College of Arts and Sciences

In partial fulfillment of the requirements

For the degree of

Master of Science

in

Psychology

Tracy L. Morris, Ph.D., Chair

Barry A. Edelstein, Ph.D.

Amy L. Gentzler, Ph.D.

Department of Psychology

Morgantown, West Virginia

2012

Keywords: Social anxiety, Parental control, Parental warmth

Copyright 2012 Jonathan M. Ortega 


\begin{abstract}
Influence of Parent-Child Communication Styles on Social Anxiety: Observation During a Film Discussion Task
\end{abstract}

By Jonathan M. Ortega

This study sought to examine the relation between levels of child social anxiety and parenting communication styles, specifically parental control and criticism verbal behaviors, during a film discussion task. Additionally, the current study examined the influence of discussion instructions (unstructured vs. structured) and content of film clips (social performance, friendships and family dynamics) on parent-child dyad responses and children's perception of threat respectively. A total of 26 parent-child dyads participated in the study, with 25 dyads $(23$ mothers $(M$ age $=40.3), 2$ fathers $(M$ age $=48), 15$ girls $(M$ age $=9.7), 10$ boys $(M$ age $=10.2)$ ) included in the analyses. Parents and children completed a functioning measure of social anxiety and children also completed measures of perceived parenting style. The dyads then engaged in discussion of 6 short film clips for approximately 5 minutes each. The verbalizations of both the parents and children were coded. Higher parental social anxiety scores were found to be significantly associated with increased children's self-report paternal care $(r=.53, p<.01)$. Children's perceptions of their parents' care and overprotection behaviors were also associated with observed behaviors of control and criticism during the film discussion task. Additionally, film content category was found to significantly influence children's perception of threat, with more children observed to find the social performance film clip anxiety provoking compared to the family dynamic and friendship film clips. The results appeared relatively consistent with prior research in the area of social anxiety and parent-child interactions (e.g. Ginsberg, Grover, Cord, \& Ialongo, 2006). Limitations of the study include small sample size and inability to examine meaningful parent gender differences in communication styles. Future research should continue to use multi-method assessment in this area of research and further examine the utility of using film clips as stimuli for parent-child discussion tasks. 


\section{Acknowledgements}

I would like to thank my advisor Tracy Morris for all of her guidance and support from start to finish on this project. Additionally, I would like to thank Amanda Costello and Steven Thompson for all of their assistance and support. Finally, I am indebted to my fellow colleagues, friends and family who supported me throughout the completion of this project. 
Table of Contents

Abstract............................................................. ii

Acknowledgements...................................................... iii

List of Appendices................................................ v

List of Tables......................................................... vi

Chapter 1: Literature Review..............................................

Family Process Factors: Parental Control and Warmth................ 2

Observational Studies............................................. 4

Chapter 2: Current Study.............................................. 10

Hypotheses................................................ 12

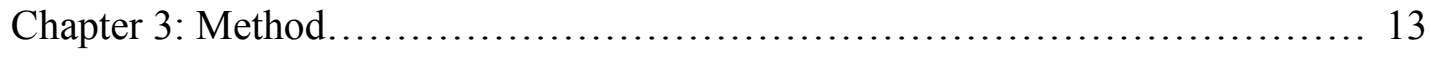

Participants.................................................. 13

Measures........................................................ 13

Procedure...................................................... 16

Chapter 4: Results................................................... 18

Chapter 5: Discussion.............................................. 21

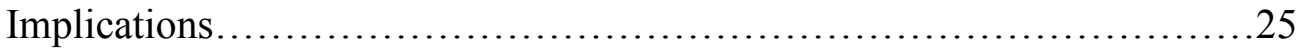

Limitations........................................................ 26

Future Directions............................................. 29

References.................................................................. 31 


\section{List of Appendices}

Appendix A: Code Definitions for Parent-Child Interaction..................... 37

Appendix B: Summaries of Film Clips used in the Film Discussion Task........... 38 


\section{List of Tables}

Table 1: Demographic Variables of Participants and Spouses................... 39

Table 2: Means, Standard Deviations and Range of Study Measures............... 40

Table 3: Means, Standard Deviations and Range of Frequencies................. 41 of Observed Parental Behaviors

Table 4: Correlations of Measures and Behavioral Observations................. 42 


\section{Chapter 1: Literature Review}

Adverse effects of social anxiety have been identified for individuals from infancy to adulthood (e.g., Beidel, Turner \& Morris, 1999; Warren, Huston, Egeland \& Sroufe, 1997; Zaider, Heimberg \& Iida, 2010). Social anxiety in children has been associated with substantial distress in various social situations, increased self-report of loneliness, lower ratings of social skills competence (Cartwright-Hatton, Tschernitz \& Gomersall, 2005), and fewer friendships (Beidel et al., 1999). In adults, social anxiety is associated with subjectively lower ratings of relationship quality (Zaider et al., 2010) and quality of life (Barrera \& Norton, 2009).

Additionally, social anxiety is highly correlated with clinical disorders including generalized anxiety disorder, depression and alcohol use disorders (Buckner \& Schmidt, 2009; Morris, 2001). The large array of impairment related to social anxiety demonstrates the importance of research into etiological factors of this disorder.

The term social anxiety refers to a set of behaviors that may occur in response to various social stimuli (Morris, 2001). Social stimuli may range from informal conversations with a peer to presenting a research paper to a room of professionals. Masia and Morris (1998) present a "triple response conceptualization" of social anxiety where overt (school refusal, escaping social situations), physiological (increased heart rate, sweating), and cognitive (thinking "No one will like me") behaviors may all interact and occur in response to social stimuli. Social anxiety is often a typical response to certain social stimuli but becomes adverse and intrusive when social functioning is compromised. These conceptualizations of social anxiety are similar to the fourth edition of the Diagnostic and Statistical Manual of Mental Disorders' description of social phobia (also known as social anxiety disorder). Social phobia is identified as "a persistent fear of social or performance situations in which embarrassment may occur (DSM-IV-TR, American 
Psychiatric Association [APA], 2000).” There is a trend in current research to use the term social anxiety, instead of social phobia, when describing a collection of maladaptive behaviors that may occur in response to social stimuli (Banerjee \& Watling, 2010; Kashdan \& Herbert, 2001; Rork \& Morris, 2009). For the purposes of this paper, social anxiety and social phobia will be used interchangeably.

Morris (2001) presents an exploratory model for the development of social anxiety disorder. Potential etiological factors discussed include a temperamental style of behavioral inhibition, family processes (including insecure attachment, controlling parenting style, restricted family sociability, and modeling of fear), peer relationship difficulties, cognitive biases, and social skills deficits. Consistent with a developmental psychopathology framework, the model reflects multiple entry and exit points, with substantial diversity in etiological paths. Consistent with the rationale of the present study, the literature review will focus on the influence of family processes on the development of social anxiety disorder, particularly the role of parenting styles and parent-child communication.

\section{Family Process Factors: Parental Control and Warmth}

A substantial amount of literature has demonstrated an association among parenting behaviors and the development of social anxiety (Arrindell, Emmelkamp, Brilman, \& Monsma, 1983; Bruch \& Heimberg, 1994; Eastburg \& Johnson, 1990; Parker, 1981; Rapee \& Melville, 1997). The influence of parental control and rejection has been noted in particular. Parental control and overprotection is characterized by a reluctance to grant autonomy to the child, intrusion, and encouragement of dependency (Rapee, 1997). Parental rejection is characterized by low expressions of warmth or active expressions of hostility. 
Parker (1979) examined the influence of perceived parenting style among 81 adults (52 females, 29 males, $M=39.1$ years old; 41 with social phobia; 40 with agoraphobia) using the Parental Bonding Instrument (PBI; Parker, Tupling, \& Brown, 1979). Participants in the social phobia group endorsed both their parents as less caring and more overprotective or controlling than a non-clinical comparison sample. Participants in the agoraphobia group only differed from control participants in lower levels of maternal care. These findings are significant because Parker was able to use the PBI to show significant differences in perceived parental styles between two groups of individuals with differing anxiety disorders. The relation between the PBI and psychopathology has been examined extensively (Faravelli, Panichi, Pallanti, Paterniti, Grecu, \& Rivelli, 1991; Gladstone \& Parker, 2005; Wilborg \& Dahl, 1997). The PBI is one of the most used measures of perceived parenting style and has been demonstrated to be stable over time, regardless of mood state and life experience (Parker, 1990; Wilhelm, Niven, Parker \& Hadzi-Pavlovic, 2005).

Anhalt and Morris (2008) examined the relation between adults' perception of parenting styles and levels of internalizing problems, which included depression, generalized and social anxiety. Retrospective measures of parenting style and self-report measures of internalizing disorders were administered to 434 undergraduates ( $65 \%$ female, $35 \%$ male, $M=19.10$ years old). The perceived parenting styles measured include parental care, control, criticism, sociability and parent-adolescent attachment. The Social Phobia and Anxiety Inventory (SPAI), Beck Anxiety Inventory (BAI) and Beck Depression Inventory-II (BDI-II) measured social anxiety, generalized anxiety and depression respectively. The authors found that maternal factors accounted for $11 \%$ of the variance in the participants' SPAI scores while paternal factors accounted for $9 \%$ of the variance. Further analysis of beta weights indicated that maternal 
sociability and criticism along with paternal care, protection and sociability were statistically significant predictors of social anxiety scores. Socially anxious adults were more likely to perceive their mothers as exhibiting high levels of overprotection and low levels of care. Additionally, fathers were perceived as exhibiting high levels of both care and overprotection.

\section{Observational Studies}

Krohne and Hock (1991) conducted an early observational study of parent-child interaction and parental restriction. Forty-seven mother-child dyads ( 24 boys, 23 girls; aged 1013 years) were observed attempting to assemble a puzzle cube. Groups were defined as highanxious versus low-anxious based on their scores on the State-Trait Anxiety Inventory for Children (Spielberger, 1973). Mothers of high-anxious girls were observed to engage in more restrictive behaviors (e.g., taking and retaining control of the puzzle cube) than the mothers of low-anxious girls. Opposite results were found for boys, with mothers of low-anxious boys demonstrating more engagement during the puzzle task.

Barrett, Rapee, Dadds, and Ryan (1996) examined children's responses to hypothetical situations and observed aspects of maternal and paternal control during an interaction task. The target anxious group consisted of 152 children (aged 7-14 years) who met criteria for a principal anxiety disorder diagnosis, including separation anxiety disorder $(n=37)$, overanxious disorder $(n=57)$, simple phobia $(n=27)$, or social phobia $(n=31)$ according to DSM-III-R criteria (APA, 1987). The anxious group was compared to a non-clinical control group $(n=26)$ and an oppositional defiant disorder (ODD) group $(n=27)$. Parent-child dyads were given 12 ambiguous, hypothetical situations and were asked to answer what happened (open-ended), what option was most likely (close-ended) and what would they do in each situation. The researchers found that children diagnosed with an anxiety disorder, compared to the non-clinical control 
group, were more likely to interpret ambiguous situations as threatening and more likely to provide avoidant solutions to those situations. Children diagnosed with ODD were more likely to interpret ambiguous situations as threatening and provide aggressive solutions compared to both anxious and non-clinical control groups. Additionally, the parent-child dyads were observed discussing two of the ambiguous, hypothetical situations for five minutes each. Children in the anxious group chose fewer avoidant solutions before the family discussion $(M=29.7)$ than after the discussion $(M=67.8)$, suggesting enhanced perception of threat via parental modeling of fear or verbal transfer of information.

Dadds, Barrett, Rapee and Ryan (1996) further analyzed the discussion component of the Barrett et al. (1996) study by more closely examining the content and communication style parents used with their children. The group selected for further analysis was comprised of 66 children randomly selected from the original 152 members of the anxious group. The primary diagnoses for this subgroup included overanxious disorder $(n=24)$, separation anxiety disorder $(n=21)$, simple phobia $(n=6)$, or social phobia $(n=15)$. This group was compared to a nonclinical control group $(n=18)$ and an oppositional defiant/conduct disorder group $(n=16)$. The researchers coded each utterance from the mother or father-child dyad by identifying four dimensions: speaker, listener, content of speech and affect of each family member. A series of analysis of variances (ANOVAs) were conducted with group membership (anxious, non-clinical, and ODD) as the independent variable and the four coding dimensions as the dependent variables. Dadds et al. (1996) found that mothers of children in the anxious group were significantly less likely to listen to and agree with their child than mothers of children in the nonclinical group. Additionally, the authors conducted conditional probabilities of avoidant and prosocial responses. They found that mothers and fathers of anxious children were more likely to 
retort with an avoidant, rather than a pro-social, response when their children provided an avoidant solution.

Siqueland, Kendall, and Steinberg (1996) examined parental warmth, acceptance and psychological autonomy using self-report and observational measures. Similar to prior research on anxiety and family process (Barrett et al., 1996; Dadds et al., 1996; Dumas, LaFreniere \& Serketich, 1995; Krohne \& Hock, 1991; Parker, 1979; 1981), the authors hypothesized that low levels of parental warmth and high levels of parental control would be associated with child anxiety. Seventeen participants (13 boys and 4 girls, $M=10$ years, 9 months) diagnosed with an anxiety disorder (14 overanxious disorder, 3 separation anxiety disorder) and their parents (15 two parent families, 2 single parent families) participated in 4 six-minute discussion tasks where parental behavior was coded for warmth and control. The control group consisted of 27 children (17 males, 10 females, $M=11$ years, 2 months), with no anxiety diagnosis, and their parents (19 two parent families, 8 single parent families). Parents were determined to encourage autonomy if they engaged in behaviors such as soliciting their child's opinion, encouraging their child to think independently and tolerating differences in opinion. Siqueland et al. (1996) found that parents of children with anxiety disorders were observed to grant less psychological autonomy than were parents of children in the control group. Children with anxiety disorders rated their parents as less accepting than children in the control group, although there was no significant difference in observed parental warmth during the observation task.

Hudson and Rapee (2001) analyzed parental control and warmth by observing motherchild dyads solving complex, cognitive puzzle tasks. Participants consisted of 95 children (aged 7 to 15 years old) and their mothers. Groups were defined by diagnostic status: 43 children with anxiety disorders (20 males, 23 females), 20 with oppositional defiant disorder (17 males, 3 
females), and 32 non-clinical (17 males, 15 females). Mother-child dyads were observed for five minutes while engaged with a tangram puzzle and then a scrabble task. The authors measured the degree of parental control and warmth on ten global scales including degree of unsolicited help (control) and mother's degree of positive affect (warmth). The results showed that mothers of children in the anxiety disorder and oppositional defiant disorder groups were significantly more involved than mothers of children in the non-clinical group during the observation tasks. Additionally, mothers of children with anxiety disorders were observed to be significantly more critical than mothers of children in the non-clinical group. When comparing the observational and self-report data, children's reports of anxiety symptoms were significantly correlated with the degree of maternal involvement and negativity.

Hummel and Gross (2001) examined differences in the quality and quantity of verbalizations by parents of children with high and low levels of social anxiety. Children were categorized based on their scores on the Social Phobia and Anxiety Inventory for Children (SPAI-C) into high social anxiety $(n=15, M=11.8$ years old) and low social anxiety $(\mathrm{n}=15, M$ $=11.9$ years old) groups. Children attempted to solve a difficult jigsaw puzzle task where they were observed for three, 10-minute intervals during which their mother; father; then both parents assisted them with the task. Parents' statements during the observation period were coded as command, suggestion, explanation, question, positive feedback, and negative feedback statements. The experimenters found that parents of children in the low social anxiety group made more verbalizations during the task and these verbalizations included more suggestions, explanations and less negative feedback than parents of children in the high social anxiety group. Contrary to prior observational research on family process factors (Dadds et al., 1996; Dumas et al., 1995; Krohne \& Hock, 1991; Siqueland et al., 1996), Hummel and Gross (2001) did not find 
command/parental control statements to be significantly different between groups. Conditional probability analyses found that children with high levels of social anxiety were more likely to respond with negative verbalizations after receiving negative feedback from one of their parents. The authors argue that "asynchronous responding" from parents, including a high degree of negative feedback and contradictions, may influence the development of social anxiety in children.

Greco and Morris (2002) investigated the association of father-child interactions and social anxiety in children. The authors hypothesized that children with high levels of social anxiety (as measured by the SPAI-C) would perceive their fathers as more overprotective than children with low levels of social anxiety. Additionally, fathers of children with high levels of social anxiety would demonstrate more controlling behavior, including commands and physical takeover of a task, than fathers of children with low levels of social anxiety during the observation period. Twenty-two children with high social anxiety (10 females, 12 males, $M=11$ years old) and 26 children with low social anxiety (13 females, 13 males, $M=11.73$ years old) engaged in an observation task with their fathers as well as completing self-report measures of their father's parenting style. The father-child dyads were observed for 10 minutes attempting to create two origami figures. This novel observation task was chosen because of its potential to elicit behaviors associated with parental control. Greco and Morris (2002) found that fathers of children with high levels of social anxiety exhibited more physical control than fathers of children with low levels of social anxiety. No significant difference was found between fathers' use of commands and frequency of rejecting behavior. Additionally, children's perceptions of their father's parenting style did not differ based on group (high vs. low social anxiety). The 
study supports parental control, but not rejection/lack of warmth, as a potential etiological factor related to social anxiety.

Ginsberg, Grover, Cord, and Ialongo (2006) conducted a study with 50 mothers (25 diagnosed with an anxiety disorder) who were primarily identified as African-American (86\% vs. $14 \%$ Caucasian) and their children (24 males, 26 females; $M=5.86$ years old). Mother-child dyads were observed during structured (Etch-A-Sketch) and unstructured (child free play) tasks. The authors hypothesized that mothers with anxiety disorders would demonstrate higher levels of control, criticism and anxious behaviors in the structured task compared to the unstructured task. Anxious behaviors were defined as mother's "expressions of fear, worry or perfectionism." The results showed that mothers in both groups exhibited higher levels of controlling and anxious behavior while participating in the structured compared to the unstructured task. However, higher levels of criticism were found for only anxious mothers across both structured and unstructured tasks. This study presents a unique perspective to the family process literature by examining potential differential results based on type of observational task.

Rork and Morris (2009) attempted to replicate prior research on family process factors using a multi-method approach. Thirty-two children (15 females, 17 males, $M=11.63$ years old) and their mothers and fathers were given retrospective and self-report measures of perceived parental style, generalized anxiety and social anxiety, respectively. Once the families completed these measures, two to three families at a time were placed in a room and observed for ten minutes without instructions. After ten minutes, the experimenter entered the room and asked the children to create a skit from three possible scenarios, while the children and parents' behaviors were observed and coded. The authors found that perceived maternal and paternal overprotection was associated with social anxiety for the whole sample but perceived maternal overprotection 
was significantly related to male children's social and general anxiety self-report scores. Additionally, when analyzed by gender, maternal negative commands during the observation task related to boys' social anxiety scores, accounted for $58 \%$ of the variance, while paternal idea generations related to girls' social anxiety scores, accounted for 35\% of the variance. Gender appears to be a potential moderating factor between family process factors and development of generalized and social anxiety. The study demonstrates the importance of using multiple methods to investigate family process factors.

\section{Chapter 2: Current Study}

The present study attempts to add to the existing literature on family process factors related to the development of social anxiety. Parents and children completed measures of social anxiety and then watched a series of film clips. They were asked to discuss the content of these clips with each other. The film clips served as a visual representation of hypothetical scenarios for the dyads to discuss (Barrett et al., 1996; Dadds et al., 1996). Research has demonstrated the utility of using film clips (Dunsmore, Her, Halberstadt \& Perez-Rivera, 2009), but no known studies have used this type of stimuli when attempting to observe parent-child interactions related to social anxiety. The study focused on discussions of film clip content, in order to determine if social anxiety was associated with parent-child communication styles, specifically high levels of control and low levels of warmth.

The research discussed in the literature review demonstrates support for the influence of parental control, and to a lesser degree parental warmth, on the development of social anxiety. Parental warmth has not been consistently shown to predict social anxiety in children (e.g., Siqueland et al., 1996; Greco \& Morris, 2002), but was examined as a potential factor in the current study. Parental control was operationally defined as a verbal interruption or command 
statement from the parent toward the child. Parental warmth was operationally defined as providing praise during discussion of the film clip. Low levels of parental warmth included ignoring the child's verbalizations, as well as rejecting and critical statements directed toward the child. Code definitions are presented in Appendix A.

The present study addressed certain limitations of past research. Early research relied primarily on retrospective reports of perceived parenting among clinical groups, raising concerns about hindsight bias. More recent research has moved toward observation of parent-child interaction among clinical and community samples. Several studies have used challenging puzzle or origami tasks as stimuli (Dumas et al., 1995; Greco \& Morris, 2002; Hummel \& Gross, 2001). Puzzle tasks often are used because they tend to elicit behaviors related to parental control and criticism. However, one of the limitations of using a complex puzzle task as a stimulus is that parents and children are not likely to engage in this type of activity on a regular basis. Such tasks also may allow for more physical control and intervention than strictly verbally-mediated tasks. Studies that have relied primarily on discussion of hypothetical scenarios may be subject to the relatively limited conceptual abilities of children.

The present study addressed these limitations by using a multi-method approach, examining parental control and warmth through use of self-report measures and direct observation during a discussion task. Short film clips (3-5min each) were used as stimuli for discussion. Watching films is a routine activity for most families and may be considered more naturalistic than puzzle tasks. Visual stimuli also may be better understood by children than the verbally presented ambiguous scenarios used in previous research. The current study also adds to the literature on family process factors by examining interaction of behaviors in the context of the instructions given to the parent-child dyads (less vs. more structured) for each discussion 
phase, and content category of stimuli (family dynamics, friendship, social performance). The type of instruction provided in the current study was similar to the structured vs. unstructured tasks used in the study by Ginsberg et al. (2006). The current study examined the effect differing levels of structure in discussion instructions have on observed parenting behaviors of parental control and criticism; an effect that was found using interaction tasks with differing levels of structure in the study by Ginsberg et al. (2006). Although there are many differences in sample characteristics and methodology between the current study and the Ginsburg et al. (2006) study, level of structure was examined in an attempt to determine if structured instructions, a less salient manipulation compared to structured vs. unstructured play tasks, could still elicit some of the same parenting behaviors reported by Ginsburg et al. (2006).

\section{Hypotheses (H)}

H1: Child social anxiety will be associated with parental social anxiety, child-reported parental control, and observed parental control and criticism during the film discussion task.

H2: Use of structured (vs. unstructured) instructions will result in higher frequencies of controlling, critical, and threat-enhancing verbalizations on the part of parents during the film discussion task.

H3: Child perception of threat (high/low) and proposed solution (avoidant/proactive) under the structured instruction condition of the film discussion task will differ by film content category (i.e., family dynamics, friendships, social performance). The film clip reflecting social performance is expected to generate the highest frequency of perceived threat and avoidant responses. 


\section{Chapter 3: Method}

\section{Participants}

The participants were 26 parent-child dyads recruited from the Morgantown, West Virginia area and surrounding counties. One parent-child dyad was excluded from analyses due to not agreeing to be video recorded during the Film Discussion Task. An a priori G*Power analysis at $80 \%$ power with effect sizes ranging from small to medium recommended that approximately 24 parent-child dyads be recruited for the study for the analyses proposed. The

final sample of 25 dyads consisted of 23 mothers $(M$ age $=40.3), 2$ fathers $(M$ age $=48), 10$ boys $(M$ age $=9.7$ years $)$ and 15 girls $(M$ age $=10.2$ years $)$. Children recruited for the study were between the ages of 8-12 years old, in order to ensure that they would be able to fully understand and complete the Social Phobia and Anxiety Inventory for Children. There were no exclusion criteria for the parents in the study. The ethnic composition of participating parents was: 21 Caucasian, 1 African-American, 1 Hispanic, and 1 self-identified as "Other." The ethnic composition of participating children was: 20 Caucasian, 1 African-American, 1 Hispanic, 1 Mixed, and 1 self-identified as “Other." Parent-child dyads received $\$ 30$ for their participation in the study which took approximately 90 minutes to complete. Additional demographics for the sample are presented in Table 1.

\section{Measures}

Social Phobia and Anxiety Inventory (SPAI): The SPAI (Turner, Beidel, Dancu, \& Stanley, 1989) is a 45 item self-report inventory that measures symptoms of social anxiety in individuals aged 14 years and older. Items are related to the cognitive, behavioral and somatic dimensions of social anxiety. The measure has demonstrated high test-retest reliability, internal consistency, and discriminant validity (Beidel, Turner, Stanley, \& Dancu, 1989; Peters, 2000; Turner et al., 1989). 
Social Phobia and Anxiety Inventory for Children (SPAI-C): The SPAI-C (Beidel, Turner, \& Morris, 1995) is a 26 item self-report measure to assess social anxiety symptoms in children aged 8-14 years. A three-point scale is used to answer the items, ranging from 0 (never or hardly ever) to 2 (almost always or always). Twelve of the 26 items have sub-levels in which the child is asked to report their responses in different situations (e.g. with "boys and girls I know," "boys and girls I don't know," and "adults"). The SPAI-C is scored by calculating the mean for each of the statements requiring multiple responses, and then by summing the scores of the 26 items. The maximum score a child may obtain is 52 . A score of 18 has been indicated as an appropriate cut-score when screening for children who meet criteria for social anxiety disorder.

Beidel, Turner, Hamlin and Morris (2000) demonstrated that the SPAI-C has adequate external validity by finding that SPAI-C scores correlated with parental reports of child social fears and independent observer ratings of child behavioral skills. Additionally, the authors demonstrated above-average discriminative validity due to finding that the SPAI-C was able to effectively differentiate children with social phobia from children with other types of anxiety disorders (Beidel et al., 2000). The SPAI-C also is significantly correlated with other measures of child anxiety, such as the Social Anxiety Scale for Children, Revised (SASCR; La Greca, 1998; La Greca \& Stone, 1993; $r=.63, p<.001$ ), suggesting that both measures assess similar, but not identical, constructs (Morris \& Masia, 1998). More specifically, Beidel, Turner, and Fink (1996) demonstrated adequate convergent validity for the SPAI-C by finding SPAI-C scores significantly correlated with children's average number of distressing social events reported per day on a daily diary $(r=.50, p<.025)$, and moderately correlated with average Self-Assessment Manikin (SAM) distress ratings of those events $(r=.41, p=.07)$. 
Parental Bonding Instrument (PBI): The PBI (Parker, Tupling, \& Brown, 1979) originally was designed as a 25 -item retrospective measure completed by asking individuals to remember their own parents' parenting styles during the first 16 years of their life. The PBI yields two scales: Care (warmth; consisting of 12 items) and Overprotection (control; consisting of 13 items). Both scales are scored on a four-point Likert-type scale from zero to three. The Care scale measures responses on a continuum from warmth/affection to rejection, with higher scores indicating perception of a higher level of parental warmth, and lower scores representing a perception of rejection. The Overprotection scale measures responses on a continuum from control to autonomy, with higher scores indicating perception of a higher level of parental control, and lower scores representing a perception of parental encouragement of autonomy. The PBI has been used extensively with a wide array of clinical and community samples across several countries. Warner and Atkinson (1988) found high levels of test-retest reliability for the PBI, with correlations ranging from 0.79 to 0.88 . Favaretto, Torresani, and Zimmermann (2001) found adequate internal consistency for the PBI, with Cronbach's alpha ranging from 0.67 to 0.88 for the maternal- and paternal- care and overprotection scales. Additionally, Parker (1993) demonstrated satisfactory construct and convergent validity for the PBI, and found the PBI to be independent of mood effects.

In this study, the researchers used a revised version of the PBI for administration to children to report on their current perceptions of their parents' child-rearing behaviors. The child completed one PBI form for their mother, and another PBI form for their father. The primary changes on this revised version from the original version are (a) presentation of all items in the present tense (given the current status of the issues presented) and (b) elimination of double negative items (to avoid confusing the child). Sample items include: "My mother speaks to me in 
a warm and friendly voice," and, "My father is emotionally cold" for the Care scale and, "My father invades my privacy," and, "I am never allowed to do what I want" from the

Overprotection scale. This revised version has been used previously and found to have adequate psychometric properties (Greco \& Morris, 2002, Rork \& Morris, 2009).

\section{Procedure}

Participants were recruited from flyers, emails, and word of mouth. Upon arrival for their appointment, parent-child dyads were presented with consent and assent forms. This involved a short description of the study and their rights as participants. The dyad was then escorted to separate rooms to complete the self-report measures. The experimenter continued to be available to answer questions and clarify instructions.

Film discussion task. Following completion of self-report measures, the parent-child dyad was reunited and presented with a series of short film clips. A discussion phase followed after presentation of each film segment. The content of these short film segments (approximately three to five minutes long) addressed issues relevant to children, including family dynamics, friendships, and social performance. These clips allowed for ambiguity with respect to perceived threat on the part of the child and opportunity for parental control and criticism (see Appendix B for brief descriptions).

Parent-child dyads viewed all six film clips and received two different types of instructions. The two types of instructions given to the parent-child dyads differed based on their level of structure. The unstructured instruction given to the parent-child dyads was the following: "Please discuss what you just saw with your child for five minutes. The experimenter will notify you when the allotted time is over." This structured instruction was typed on a sheet of paper and the dyad was directed to read the instruction and begin discussing the film clip. The instruction 
allowed for the parent-child dyads to discuss any relevant issue from the clip, even topics not directly related to the scenario they just viewed. This instruction was given to the dyads before the discussion task for the first three clips (with each clip representing one of the three content categories: family dynamics, friendships, social performance). A structured instruction was presented prior to discussion of each of the second set of three film clips. An example of a structured discussion instruction is the following: "Please discuss which parts of the situation presented in the film clip might make you feel anxious or nervous. What would you do if you were in that situation?"

Each parent-child discussion lasted for five minutes and was recorded by a video camera in the same room as the participants. The discussion task, related to a particular film clip, was terminated before the five minute mark if there was 20 seconds of silence between the parent and child. The content and communication style of the parents and children was coded at a later date. The experimenter moved to an adjacent room after presenting the discussion instructions to the parent-child dyad, while still able to hear but not see the discussion. After five minutes had elapsed, the experimenter reentered the room and notified the dyad that their allotted discussion time was over. Subsequently, the experimenter played the next video clip and presented the discussion instructions before once again moving to the adjacent room. Once the final discussion was complete, the parent was presented with $\$ 30$ for the dyad's participation. Total participation time was approximately 90 minutes for each parent-child dyad.

Coding. Following completion of the study, the video tapes of the film discussion task were coded for different types of verbal communication (see Appendix A). Coding was conducted within 10-second intervals for a maximum of five minutes per discussion segment. After 20 seconds of silence from both dyad partners the experimenter discontinued the 
discussion and no other verbalizations were coded. A total of 6 parent-child dyads had their discussions terminated due to meeting the discontinue criteria. The 6 parent-child dyads met the discontinue criteria for an average of 2.8 film clip discussions and the average length of time all 25 dyads discussed the clips was 28.91 minutes. Means, standard deviations and range for the parental observed behaviors included in the analyses are presented in Table 3 and include the parental behaviors for the 6 dyads who met discontinue criteria. Inter-rater reliability was calculated by having another graduate student, who was trained in the coding system; re-code the statements of five of the parent-child dyads. Overall interrater percent agreement, calculated as agreement from interval to interval between the experimenter and the reliability coder, was $r=$ .74 for parents' verbal statements and $r=.79$ for children's verbal statements during the film discussion task. Additionally, children's perceived threat and proposed solution were coded for the discussions on the second set of film clips, using the structured instruction. Overall interrater percent agreement was $r=.88$ for children's perceived threat and $r=.92$ for children's proposed solution for film clips in the structured instruction condition. Perceived threat was coded as either "anxious" or "not anxious" and proposed solution was coded as either "avoidant" or "proactive."

\section{Chapter 4: Results}

\section{Hypothesis 1}

Pearson correlations were used to test the first hypothesis that child reported social anxiety would be associated with parent reported social anxiety, child reported parental control and criticism, as well as with observations of parental criticism and control during the film discussion task. Means, standard deviations and range for all of the measures are presented in Table 2 and Pearson correlations used to test hypothesis 1 are presented in Table 4. Contrary to 
hypothesis 1 , child reported social anxiety on the SPAI-C was not significantly correlated with parent social anxiety on the SPAI, nor were parental observations of controlling behaviors (Command-Positive, Command-Negative) and critical behaviors (Verbal Interruption, CriticismOther).

Children's reports of maternal and paternal care on the PBI were significantly correlated, as were children's reports of maternal and paternal overprotection on the PBI. Parental observations of controlling (Command-Positive, Command-Negative) and critical behaviors (Criticism-Other) were significantly correlated. Parental observations of warmth behaviors (Praise-Other, Reassurance-Give) were also significantly correlated. Children's self-report of maternal control was significantly correlated with parental observations of critical behaviors (Command-Positive, Command-Negative). Children's self-report of paternal warmth and care were significantly correlated with SPAI scores, and parental observations of control (CommandNegative) and warmth (Reassurance-Give) behaviors. Finally, children's self-report of paternal control was significantly correlated with parental observations of controlling (CommandPositive, Command-Negative) and critical (Criticism-Other) behaviors.

\section{Hypothesis 2}

Paired Sample t-tests were used to examine hypothesis 2 regarding the differences between structured vs. unstructured instructions and the frequency of controlling and critical parental verbalizations. Four observed behaviors related to critical and controlling parental behaviors (positive commands, negative commands, criticism and verbal interruptions) were examined to determine if the frequency of these behaviors differed based on the type of instruction provided during the film discussion task. Participant responses were not found to differ significantly by type of instruction: positive commands $(t=.677, p=.51)$, negative 
commands $(t=1.25, p=.22)$, criticism $(t=-.097, p=.92)$ and verbal interruptions $(t=.385, p=$ $.70)$.

\section{Hypothesis 3}

McNemar's non-parametric test was used to examine hypothesis 3 regarding the effect of film content category (social performance, friendship, and family dynamics) on differences in children's perceived threat and proposed solution stated during the structured instruction condition of the film discussion task. Three pairwise comparisons were examined related to children's perceived threat as well as proposed solution in order to account for all possible combinations of film content category comparisons (i.e., social performance vs. friendship; friendship vs. family dynamics; family dynamics vs. social performance). The McNemar test was used because it evaluated if the proportion of children who perceive one film clip as threatening differ significantly from the proportion of children who perceive another film clip as threatening. The data meet the assumptions of the McNemar test due to nominal and binary data being analyzed, as well as the same children watching and evaluating all three film clips. With regard to perceived threat, $100 \%$ of children $(n=25)$ perceived the social performance clip as anxiety provoking, while only $72 \%$ of children $(n=18)$ perceived the friendship clip as anxiety provoking. The same percentages were found when comparing children who perceived high threat in social performance clips $(100 \% ; n=25)$ to children who perceived high threat in family dynamics clips $(72 \% ; n=18)$. These percentages for both comparisons were significantly different from one another based on the results of the McNemar test of dependent proportions, $p$ $=.016$, indicating that more children perceived the social performance clip as threatening compared to the other two film clip categories. Additionally, no significant results were found 
when comparing the friendship and family dynamics clips due to equal numbers of children perceiving them as highly threatening.

With regard to children's proposed solution, $16 \%$ of children proposed an avoidant solution for the social performance clip, while $12 \%$ of children proposed an avoidant solution for the friendship clip. However, these percentages were not significantly different from each other based on the results of the McNemar test of dependent proportions, $p=1.00$. Twelve percent of children proposed an avoidant solution for the friendship clip, while three percent of children proposed an avoidant solution for the family dynamics clip. These percentages were also not significantly different from each other based on the results of the McNemar test of dependent proportions, $p=.63$. Finally, $16 \%$ of children proposed an avoidant solution to the social performance clip, while three percent of children proposed an avoidant solution to the family dynamics clip. These percentages were no significantly different from each other based on the results of the McNemar test of dependent proportions, $p=.38$. However, it must be noted that the lack of differences cannot be reported with a high degree of confidence as the multiple comparisons were substantively underpowered as a function of small sample size. Power, with a medium effect size, was estimated at $2 \%$ for the analyses conducted for Hypothesis 3 . The statistical program $\mathrm{G}^{*}$ Power was used to estimate power for the preceding analyses (Faul, Erdfelder, Lang, Bucher, 2007)

\section{Chapter 5: Discussion}

The purpose of the current study was to examine the association between child social anxiety and parent-child dyad communication styles using a multi-method approach. Additionally, the use of varying instructions and differing content of stimuli also was examined to determine their impact on the observations of parental warmth and criticism, as well as child 
report of perception of threat and proposed solution. Strengths included using short film clips as stimuli for discussions between parent-child dyads compared to hypothetical scenarios (Barrett et al., 1996; Dadds et al., 1996) and puzzle tasks (e.g., Greco \& Morris, 2002). The overall findings indicate that there is a relation between children's perception of their parents' control and critical behaviors and parental observations of control and criticism.

Parent scores on the SPAI were not significantly correlated with children's scores on the SPAI-C, contrary to prior research (e.g., Rork \& Morris, 2009). Rork and Morris (2009) examined a similar question to hypothesis 1 of this study and found that boys SPAI-C scores were related to perceived maternal overprotection. However, parents SPAI scores did not account for a significant amount of variance in children's SPAI-C scores. Additionally, in the present study, children's SPAI-C scores were not associated with parental observed behaviors of control and criticism. This finding is contrary to past research (e.g. Hudson \& Rapee, 2001; Ginsberg et al., 2006; Rork \& Morris, 2009) that indicated that children's self-reported level of social anxiety was related to observed and perceived parental behaviors of control and criticism.

Sample differences in previous research in this area may account for the non-significant findings related to the associations between parents' SPAI scores, children's SPAI-C scores and observed parental behaviors of control and criticism. For example, in the study conducted by Hummel and Gross (2001), experimental and control groups were created based on children's SPAI-C scores (using a score of 29 or higher for the experimental group and 15 or lower for the control group). Additionally, in the study conducted by Ginsberg et al. (2006), mothers were separated into groups based on the presence of having an anxiety disorder, as well as children ranging in age from 5 to 8 years old. Finally, many of the studies in this area have larger sample sizes than the current study (e.g., Barrett et al., 1996; Hummel and Gross, 2001; Ginsburg et al., 
2006), which would enable more powerful analyses to be conducted and potentially more significant results to be observed that replicate previous findings in this area. Sample characteristics such as parent and child anxiety status, children's age range and parent education level, as well the type of task used to observe the interactions of parent-child dyads (difficult puzzle task compared to film discussion task) may potentially explain why non-significant correlations were found for Hypothesis 1.

However, interesting results were found with regard to child reported parental care and overprotection on the PBI and observations of parents' communication behaviors during the film discussion task. Observed parenting behaviors related to control and overprotection (positive and negative commands) were positively correlated with children's reports on the PBI of maternal overprotection. Additionally, paternal overprotection as assessed by the PBI, also was associated with observed parental positive and negative commands and criticism during the film discussion task. These results suggest that children are able to provide valid reports parental control and overprotection and their responses to paper-pencil report measures such as the PBI are not merely a function of symptom associated bias.

In the present study, critical and controlling behaviors were examined to determine if they differed based on the type of instruction (unstructured vs. structured) provided to the parentchild dyad during the film discussion task. Four specific observed parenting behaviors were examined including negative commands, positive commands, verbal interruptions and criticism. It was found the level of structure in the instructions did not appear to have any effect with regard to the overall frequency of these observed parenting behaviors. These findings do not support the proposed hypothesis or previous research in this area (e.g., Ginsberg et al., 2006). However, there are many differences in sample characteristics and methodology between the 
current study and the Ginsberg et al. (2006) study that may account for the discrepant results. Ginsberg and colleagues (2006) diagnosed half of the mothers in the study with an anxiety disorder, the mean age of the children who participated was 5.86 years old, and the structured task involved the mother-child dyads playing with an Etch-a-Sketch, while the unstructured task involved free play. In the current study, parents were not separated into groups based on a diagnosis of an anxiety disorder, the mean ages for children were higher (males: $M$ age $=9.7$ years; females: $M$ age $=10.2$ years), and the level of structure was related to different types of instructions provided to the parent-child dyad before the film discussion task. Any of these differences in sample characteristics and methodology may reasonably account for the level of structure in the current study not having an effect on the frequencies of parental control and criticism behaviors.

Film clip content category was found to be related to children's perceived threat but not proposed solution for the three film clips in the structured instruction condition of the film discussion task. Every child in the current study perceived the social performance situation as anxiety provoking. This finding with regard to threat perception was not observed for the film clips related to family dynamics and friendships. Film clip content category was not found to be related to children's proposed solution (avoidant or proactive) for the three film clips in the structured instruction condition of the film discussion task. Barrett and colleagues (1996) examined similar questions related to children's threat perception and proposed solution in response to hypothetical scenarios. The researchers found that anxious children were more likely to perceive ambiguous hypothetical scenarios as threatening and more likely to propose avoidant solutions to these situations. In the current study, the nature of the presented stimulus appeared to be more powerful than idiographic factors in determining response, at least for children's 
perception of threat in the social performance film clip. Despite children with a range of SPAI-C scores, different perceptions of the parents' care and overprotection behaviors, as well as different backgrounds and experiences, they all indicated that the social performance clip was a high threat scenario. Future investigation is needed to identify sufficiently ambiguous stimuli that may allow more fine grained analysis of threat perception by individual difference variables such as social anxiety.

\section{Implications}

The results from the present study add to the existing literature on parenting communication styles and social anxiety. Although children's social anxiety scores on the SPAI were not associated with the hypothesized parental behaviors of control and criticism, children's perceptions of their parent's care and control behaviors appear to be fairly accurate. This provides more support to the validity of the Parental Bonding Instrument (Parker et al., 1979) and demonstrates the advantages of using a multi-method assessment model when examining the relation between social anxiety and parenting communication styles. Future studies in this area may benefit from using a mulit-method approach, which includes behavioral observations and children's reports of parenting styles.

Another implication from the present study is that film clips, with some potential exceptions, can be used successfully as a stimulus in studies examining the relation between social anxiety and observed parenting behaviors. Parenting behaviors of criticism and control were observed throughout the film discussion task and were generally correlated with children's perceptions of their parents' care and overprotection behaviors. Future researchers may be able to include film clips as stimulus material in studies that examine the relation between parenting behaviors and social anxiety, as well as generally with studies investigating parent-child 
communication. Although it should be noted that the types of film clips used may have a differential impact on results related to anxiety, such as perceived threat of the hypothetical situation, which was found in hypothesis 3 in the current study. As was stated in the introduction, film clips may be easier for younger children to understand than a written hypothetical scenario and may be more similar to what would occur between parents and children in the real world. Future research is needed however to determine potential differential response to graphically displayed material (as in film clips including visual and auditory content) versus hypothetical material presented solely in written form. In order to advance this line of research, stimuli are needed that elicit a range of responses, neither so innocuous that no child would experience even the slightest arousal, nor so threatening that every child would perceive threat and fear.

\section{Limitations}

One limitation of the present study is the small sample size of participants. Only 25 parent-child dyads were included in the analysis for the study. Small sample size is associated with lower power and smaller effect sizes for study results (Bernstein, 2008). Power, with a medium effect size, was estimated at 33\% for the analyses conducted for hypothesis $1,42 \%$ for analyses conducted for hypothesis 2 , and $2 \%$ for analyses conducted for hypothesis 3 . The statistical program $\mathrm{G}^{*}$ Power was used to estimate power for the analyses conducted for each of the hypotheses (Faul et al., 2007). Another limitation related to small sample size is being unable to directly examine the influence of gender with regard to the association between child social anxiety and parenting communication behaviors. Additionally, parent-child dyads that participate in a laboratory study may not be representative of all parents and children, thus limiting the generalizability of the findings. Specifically, parents and children who have particularly high 
levels of social anxiety and avoidance may be unlikely to participate in these types of studies, further limiting the extent of the current findings.

Results may not be generalizable to families from differing socioeconomic groups. Many of the parents had a graduate education compared to high school or undergraduate education (see Table 1). It is possible that parents with higher levels of education may interact with their children differently than parents with lower levels of education. Previous research by Callhan and Eyberg (2010) indicates that higher socioeconomic status (SES) in mothers, which is subsequently associated with higher educational achievement, may be associated with more maternal prosocial talk in a sample of mothers and 3-6 years olds. However, research by Chen and Berdan (2006) found that negative behaviors (e.g., angry, demanding) were more reciprocal and strongly correlated between parents and adolescents in high SES families compared to low SES families, and this reciprocity actually lead to higher relationship quality. These somewhat conflicting findings in past research indicate the importance of further examining the influence of SES and related factors, like parental educational achievement, in future research examining parent-child interactions. Previous research on SES and parent-child communication styles provides additional rationale for the limited generalizability of the current findings due to family SES not taken into account when recruiting parent-child dyads.

A benefit and a potential limitation of the current study is the use of film clips in the place of hypothetical scenarios. Although film clips appear to provide a stimulus that is more similar to real life stimuli that parents and children might discuss, the study was still conducted in a laboratory setting with restrictions on the length of the film clip and discussion. In the present study parents were asked to speak for five minutes after watching a short film clip. This procedure is most likely not what would actually happen between parents and children in the 
context of watching a film. It should be noted that some parent-child dyads appeared to have difficulty finding something to discuss for the whole five minutes, with six dyads meeting the discontinue criteria for having at least one film clip discussion where there were 20 seconds of silence. Subsequently, it is likely that the way parents and children communicated at the beginning of each film clip discussion, as well as the beginning of the experiment was different from how the dyads interacted at the end of each film clip and the end of the experiment possibly due to effects of fatigue. Not taking this into account in the analyses is another potential limitation. The fact that there were moments in the current study where parents and children were attempting to find things to talk about may have influenced parents' and children's' communication styles in a manner that would make it different from how they would normally communicate.

Another limitation of the study with regard to the film clips is that the clips were taken from actual films. Although this does allow for the film clips to be more generalizable to actual stimuli that may occur in the real world, different parent-child dyads appeared to have varying degrees of knowledge of these film clips. The parent-child dyad's previous experience with these film clips may introduce more error into the findings than would a procedure that involved a novel hypothetical situation task (e.g. Barrett et al., 1996). Parents and children may have communicated differently after watching a film clip they had previous experience with compared to a film clip that was completely novel. These different types of communication styles may influence the observed frequencies of the parenting behaviors of interest, including control and criticism.

Lastly, parents and children may have perceived the true purpose of the study by filling out the measures of anxiety before engaging in the film discussion task. Parents may have tried 
to direct the discussion to more anxiety-focused topics because they felt that this was the goal of the study. Subsequently, this knowledge may have influenced children's perceived threat and proposed solutions observed during the film discussion task, although the structured instructions did involve having the dyads discuss anxiety provoking situations. Additionally, parents attempting to focus the discussion on anxiety topics during the unstructured instruction condition of the film discussion task may have engaged in more critical and controlling behaviors due to parents trying to keep their children focused. If these types of behaviors occurred it may influence the observations of parenting behaviors of control and criticism.

\section{Future Directions}

Future research should continue to use multi-method assessment when examining the relation between childhood social anxiety and parenting communication styles of control and criticism. This is a trend in more recent research (e.g. Greco \& Morris, 2002; Ginsberg et al., 2006; Rork \& Morris, 2009) that should continue in this area. Additionally, the use of film clips as stimuli should continue to be examined in research on parenting behaviors of control and criticism as well as with other research on parent-child communication styles. The current study was able to demonstrate that parenting behaviors of control and criticism can be elicited from a discussion that occurs after watching a short film clip and that these behaviors were actually associated with children's perceptions of parents' care and overprotection behaviors. Future research also should continue to assess for the different effects that film clips with different content areas may have on parent and child verbalizations. Preliminary findings in the present study appear to demonstrate that film content may affect children's perception of threat. However, future research should examine this effect further and determine if parenting behaviors of control and criticism may vary based on film content. Ideally, future research may be able to 
develop different validated and replicated film clips that researchers may be able to use as stimuli to examine parent-child communication styles. Furthermore, if future researchers were able to film and record their own film clips, this would likely address some of the limitations of using film clips in parent-child interaction research, such as history effects and being able to film visual interpretations of hypothetical scenarios used in prior research (e.g., Barrett et al., 1996). Additionally, both mothers and fathers should continue to be examined in future research. The current study did include two fathers in the analysis but this was insufficient in order to examine gender differences in their parenting and communication style compared to mothers. Preliminary analyses examining child gender in the current study indicated that there were some differences in how parents behaved with male and female children. For example, child self-reported maternal care was significantly correlated with high observed parental verbal interruption behavior for boys but not girls in the dyad. Also, child self-reported paternal care was significantly correlated with lower observed parental positive commands for girls by not boys in the dyad. Although underpowered, these preliminary analyses suggest that there may be differences in how males and females perceive their parents and how their parents actually behave in an interaction task. Greco and Morris (2002) were among the first researchers to examine father-child interactions with regard to social anxiety. Rork and Morris (2009) continued this trend by including both mothers and fathers in their study on childhood social anxiety. Future research should continue to make an effort to recruit mothers and fathers as well as equal numbers of boys and girls for studies examining parenting styles and childhood social anxiety. More research on fathers would help to replicate some of the previous findings with regard to father interaction style and childhood social anxiety and potentially discover new differences between mothers' and fathers' communication styles (e.g., Rork \& Morris, 2009). 


\section{References}

American Psychiatric Association. (1987). Diagnostic and statistical manual of mental health disorders (3rd ed., revised). Washington DC: Author.

American Psychiatric Association. (2000). Diagnostic and statistical manual of mental health disorders (4th ed., text rev.). Washington DC: Author.

Anhalt, K., \& Morris, T. L. (2008). Parenting characteristics associated with anxiety and depression: Exploring the contribution of multiple factors. Journal of Early and Intensive Behavioral Intervention, 5, 122-137.

Arrindell, W. A., Emmelkamp, P. M. G., Monsma, A., \& Brilman, E. (1983). The role of perceived parental rearing practices in the aetiology of phobic disorders: A controlled study. British Journal of Psychiatry, 143, 183-187.

Banerjee, R., \& Watling, D. (2010). Self-presentational features in childhood social anxiety. Journal of Anxiety Disorders, 24, 34-41.

Barrera, T. L., \& Norton, P. J. (2009). Quality of life impairment in generalized anxiety disorder, social phobia, and panic disorder. Journal of Anxiety Disorders, 23, 1086-1090.

Barrett, P. M., Rapee, R. M., Dadds, M. M., \& Ryan, S. M. (1996). Family enhancement of cognitive style in anxious and aggressive children. Journal of Abnormal Child Psychology, 24(2), 187-203.

Beidel, D. C., Turner, S. M., \& Fink, C. M. (1996). Assessment of childhood social phobia: Construct, convergent, and discriminative validity of the Social Phobia and Anxiety Inventory for Children (SPAI-C). Psychological Assessment, 3, 235-240.

Beidel, D. C., Turner, S. M., Hamlin, K., \& Morris, T. L. (2000). The social phobia and anxiety inventory for children (SPAI-C): External and discriminative validity. Behavior Therapy, $31,75-87$. 
Beidel, D. C., Turner, S. M., \& Morris, T. L. (1995). A new inventory to assess childhood social anxiety and phobia: The social phobia and anxiety inventory for children. Psychological Assessment, 7(1), 73-79.

Beidel, D. C., Turner, S. M., \& Morris, T. L. (1999). Psychopathology of childhood social phobia. Journal of the American Academy of Child and Adolescent Psychiatry, 38(6), 643-650.

Beidel, D. C., Turner, S. M., Stanley, M. A., \& Dancu, C. V. (1989). The social phobia and anxiety inventory: concurrent and external validity. Behavior Therapy, 20, 417-427.

Bernstein, B. A. (2008). An introduction to sample size and power. Journal of Developmental and Behavioral Pediatrics, 29(6), 516-522.

Bruch, M. A., \& Heimberg, R. G. (1994). Differences in perceptions of parental and personal characteristics between generalized and nongeneralized social phobics. Journal of Anxiety Disorders, 8(2), 155-168.

Buckner, J. D., \& Schmidt, N. B. (2009). Understanding social anxiety as a risk for alcohol use disorders: Fear of scrutiny, not social interaction fears, prospectively predicts alcohol use disorders. Journal of Psychiatric Research, 43, 477-483.

Callahan, C. L., \& Eyberg, S. M. (2010). Relations between parenting behavior and SES in a clinical sample: Validity of SES measures. Child \& Family Behavior Therapy, 32(2), $125-138$.

Cartwright-Hatton, S., Tschernitz, N., \& Gomersall, H. (2005). Social anxiety in children: Social skills deficit, or cognitive distortion. Behaviour Research and Therapy, 43, 131-141.

Chen, E., \& Berdan, L. E. (2006). Socioeconomic status and patterns of parent-adolescent interactions. Journal of Research on Adolescence, 16(1), 19-27. 
Dadds, M. R., Barrett, P. M., Rapee, R. M., \& Ryan, R. M. (1996). Family process and child anxiety and aggression: An observational analysis. Journal of Abnormal Child Psychology, 24(6), 715-734.

Dumas, J. E., LaFreniere, P. J., \& Serketich, W. J. (1995). “Balance of power”: A transactional analysis of control in mother-child dyads involving socially competent, aggressive and anxious children. Journal of Abnormal Psychology, 104(1), 104-113.

Dunsmore, J. C., Her, P., Halberstadt, A. G., \& Perez-Rivera, M. B. (2009). Parent's beliefs about emotions and children's recognition of parent's emotions. Journal of Nonverbal Behavior, 33, 121-140.

Eastburg, M., \& Johnson, W. B. (1990). Shyness and perceptions of parental behavior. Psychological Reports, 66, 915-921.

Faravelli, C., Panichi, C., Pallanti, S., Paterniti, S., Grecu, L. M., \& Rivelli, S. (1991). Perception of early parenting in panic and agoraphobia. Acta Psychiatrica Scandinavica, 84, 6-8.

Faul, F., Erdfelder, E., Lang, A.-G., \& Buchner, A. (2007). G*Power 3: A flexible statistical power analysis for the social, behavioral, and biomedical sciences. Behavior Research Methods, 39, 175-191.

Favaretto, E., Torresani, S., \& Zimmermann, C. (2001). Further results on the reliability of the parental bonding instrument (PBI) in an Italian sample of schizophrenic patients and their parents. Journal of Clinical Psychology, 57(1), 119-129.

Ginsberg, G. S., Grover, R. L., Cord, J. J., \& Ialongo, N. (2006). Observational measures of parenting in anxious and nonanxious mothers: Does type of task matter? Journal of Clinical Child and Adolescent Psychology, 35(2), 323-328. 
Gladstone, G., \& Parker, G. (2005). The role of parenting in the development of psychopathology: An overview of research using the parental bonding instrument. In Hudson, J. L., \& Rapee, R. M. (Eds.), Psychopathology and the family (pp. 21-33). New York, NY: Elsevier Science.

Greco, L. A., \& Morris T. L. (2002). Paternal child-rearing style and child social anxiety: Investigation of child perceptions and actual father behavior. Journal of Psychopathology and Behavioral Assessment, 24(4), 259-267. doi: 10.1023/A:1020779000183

Hudson, J. L., \& Rapee, R. M. (2001). Parent-child interactions and anxiety disorders: An observational study. Behaviour Research and Therapy, 39, 1411-1427.

Hummel, R. M., \& Gross, A. M. (2001). Socially anxious children: An observational study of parent-child interaction. Child and Family Behavior Therapy, 23(3), 19-40.

Kashdan, T. B., \& Herbert, J. D. (2001). Social anxiety disorder in childhood and adolescence: Current status and future directions. Clinical Child and Family Psychology Review, 4(1), 37-61.

Krohne, H. W., \& Hock, M. (1991). Relationships between restrictive mother-child interactions and anxiety of the child. Anxiety Research, 4, 109-124.

La Greca, A. M. (1998). Manual for the Social Anxiety Scales for children and Adolescents (new ed.). Miami, Fl: Author.

La Greca, A. M., \& Stone, W. L. (1993). Social anxiety scale for children-revised: Factor structure and concurrent validity. Journal of Clinical Child Psychology, 22, 17-27.

Masia, C. L., \& Morris, T. L. (1998). Parental factors associated with social anxiety: Methodological limitations and suggestions for integrated behavioral research. Clinical Psychology: Science and Practice, 5(2), 211-228. 
Morris, T. L. (2001). Social Phobia. In M.W. Vasey \& M. R. Dadds (Eds.), The developmental psychopathology of anxiety (pp. 434-458). New York: Oxford University Press.

Morris, T. L., \& Masia, C. L. (1998). Psychometric evaluation of the social phobia and anxiety inventory for children: Concurrent validity and normative data. Journal of Clinical Child Psychology, 27(4), 452-458.

Parker, G. (1979). Reported parental characteristics of agoraphobics and social phobics. British Journal of Psychiatry, 135(6), 555-560.

Parker, G. (1981). Parental representation of patients with anxiety neurosis. Acta Psychiatrica Scandinavica, 63, 33-36.

Parker. G. (1990). The parental bonding instrument: A decade of research. Social Psychiatry and Psychiatric Epidemiology. 25, 281-282.

Parker, G. (1993). Parental rearing style: Examining for links with personality vulnerability factors for depression. Social Psychiatry and Psychiatric Epidemiology, 28(3), 97-100.

Parker, G., Tupling, H., \& Brown, L. B. (1979). A parental bonding instrument. British Journal of Medical Psychology, 52(1), 1-10.

Peters, L. (2000). Discriminant validity of the social phobia and anxiety inventory (SPAI), the social phobia scale (SPS) and the social interaction anxiety scale (SIAS). Behaviour Research and Therapy, 38, 943-950.

Rapee, R. M. (1997). Potential role of childrearing practices in the development of anxiety and depression. Clinical Psychology Review, 17(1), 47-67.

Rapee, R. M., \& Melville, L. F. (1997). Recall of family factors in social phobia and panic disorder: Comparisons of mother and offspring reports. Depression and Anxiety, 5, 7-11. 
Rork, K. E., \& Morris, T. L. (2009). Influence of parenting factors on childhood social anxiety: Direct observation of parental warmth and control. Child and Family Behavior Therapy, $31,220-235$.

Siqueland, L., Kendall, P. C., \& Steinberg, L. (1996). Anxiety in children: Perceived family environments and observed family interaction. Journal of Clinical Child Psychology, 25(2), 225-237.

Turner, S. M., Beidel, D. C., Dancu, C. V., \& Stanley, M. A. (1989). An empirically derived inventory to measure social fears and anxiety: The social phobia and anxiety inventory. Psychological Assessment: A Journal of Consulting and Clinical Psychology, 1(1), 3540.

Warren, S. L., Huston, L., Egeland, B., \& Sroufe, L. A. (1997). Child and adolescent anxiety disorder and early attachment. Journal of the American Academy of Child and Adolescent Psychiatry, 36(5), 637-644.

Warner, R., \& Atkinson, M. (1988). The relationship between schizophrenic patients' perceptions of their parents and the course of their illness. British Journal of Psychiatry, $153,344-353$.

Wilborg, I. M., \& Dahl, A. A. (1997). The recollection of parental rearing styles in patients with panic disorder. Acta Psychiatrica Scandinavica, 96, 58-63.

Wilhelm, K., Niven, H., Parker, G., \& Hadzi-Pavlovic, D. (2005). The stability of the parental bonding instrument over a 20-year period. Psychological Medicine, 35, 387-393.

Zaider, T. I., Heimberg, R. G., \& Iida, M. (2010). Anxiety disorder and intimate relationships: A study of daily processes in couples. Journal of Abnormal Psychology, 119(1), 163-173. 


\section{Appendix A: Code Definitions for Parent-Child Interaction}

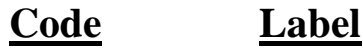

P-S Praise-Self

P-O Praise-Other (praise directed to other member of dyad)

P-J Praise-Joint (praise of mutual effort in discussion)

C-S Critical-Self

C-O Critical-Other (criticism directed to other member of the dyad)

C-J Critical-Joint (criticism of their mutual effort in discussion)

COM-P Command-Positively worded

COM-N Command-Negatively worded

QUE Question

LI Listen

IG Ignore

R-A Reassurance-ask for

R-G Reassurance-give (verbal and physical)

VI Verbal Interruption

DS-T Descriptive Statement-Task Related

OT-V Off task verbal behavior 


\section{Appendix B: Summaries of Film Clips used in the Film Discussion Task}

\section{Social Performance:}

Clip 1: A child attempts to throw a baseball in front of another group of children and fails Clip4: A child is asked to spell a word at a spelling bee in front of many people and succeeds

\section{Friendships:}

Clip 2: A child is told by two other children that they do not want to be around him because other children think he is weird and the two children get bullied because of him.

Clip 5: A child is attending a new school and is "stared down" by a group of other children when he attempts to lock up his bike.

\section{Family Dynamics:}

Clip 3: A child's parents tell him that a ride at a fair might be too scary for him but the child says that he wants to go on the ride without his parents.

Clip 6: A father talks to his child about being late for school and drawing in his math book. 
Table 1

Demographic Variables of Participants and Spouses

\begin{tabular}{|c|c|c|c|c|}
\hline Variable & $M(S D)$ & Range & Percentage $(\%)$ & $n$ \\
\hline Parent Age & $42.63(6.88)$ & $28-52$ & & \\
\hline Spouse Age & $40.96(11.01)$ & $28-57$ & & \\
\hline Child Age & $10.00(1.44)$ & $8-12$ & & \\
\hline \multicolumn{5}{|l|}{ Parent Ethnicity } \\
\hline Caucasian & & & 84 & 21 \\
\hline African American & & & 4 & 1 \\
\hline Hispanic/ Latino & & & 4 & 1 \\
\hline Other (American Indian, Asian) & & & 8 & 2 \\
\hline \multicolumn{5}{|l|}{ Spouse Ethnicity } \\
\hline Caucasian & & & 84 & 21 \\
\hline African American & & & 4 & 1 \\
\hline Hispanic/ Latino & & & 4 & 1 \\
\hline Other (American Indian, Asian) & & & 8 & 2 \\
\hline \multicolumn{5}{|l|}{ Child Ethnicity } \\
\hline Caucasian & & & 80 & 20 \\
\hline African American & & & 4 & 1 \\
\hline Hispanic/ Latino & & & 4 & 1 \\
\hline Mixed & & & 4 & 1 \\
\hline Other (American Indian, Asian) & & & 8 & 2 \\
\hline \multicolumn{5}{|l|}{ Parents Highest Level of Education } \\
\hline Did Not Complete High School & & & 4 & 1 \\
\hline High School Graduate & & & 12 & 3 \\
\hline Some College & & & 8 & 2 \\
\hline College Degree & & & 36 & 9 \\
\hline Graduate Degree & & & 40 & 10 \\
\hline \multicolumn{5}{|l|}{ Spouse Highest Level of Education } \\
\hline Did Not Complete High School & & & 4 & 1 \\
\hline High School Graduate & & & 16 & 4 \\
\hline Some College & & & 12 & 3 \\
\hline College Degree & & & 16 & 4 \\
\hline Graduate Degree & & & 52 & 13 \\
\hline
\end{tabular}

Note. One parent did not indicate age on demographic form; $\mathrm{N}=2$ 
Table 2

Means, Standard Deviations and Range of Study Measures

\begin{tabular}{lccc}
\hline \multicolumn{1}{c}{ Name of Measure } & Mean $(M)$ & $\begin{array}{c}\text { Standard Deviation } \\
(S D)\end{array}$ & Range \\
\hline PBI-C-M: Care (C) Scale & 29.52 & 4.57 & $16-34$ \\
$\begin{array}{l}\text { PBI-C-M: Overprotect } \\
\text { (OP) Scale }\end{array}$ & 14.64 & 7.11 & $4-29$ \\
PBI-C-F: Care (C) Scale & 26.72 & 5.03 & $12-33$ \\
PBI-C-F: Overprotect (OP) & 13.16 & 6.56 & $2-26$ \\
Scale & & & \\
SPAI-C: Total & 15.32 & 8.26 & $4-29$ \\
SPAI Difference Score & 46.92 & 22.28 & $-4-101$
\end{tabular}

Note. $\mathrm{N}=25$; Values rounded to two decimals places 
Table 3

Means, Standard Deviations and Range of Frequencies of Observed Parental Behaviors

\begin{tabular}{|c|c|c|c|}
\hline Parental Behavior & Mean $(M)$ & $\begin{array}{l}\text { Standard Deviation } \\
(S D)\end{array}$ & Range \\
\hline Praise-Self (P-S) & 0 & 0 & 0 \\
\hline Praise-Joint (P-J) & 0 & 0 & 0 \\
\hline Praise-Other (P-O) & 1.6 & 1.19 & $0-4$ \\
\hline Criticism-Self (C-S) & .04 & .20 & $0-1$ \\
\hline Criticism-Joint (C-J) & 0 & 0 & 0 \\
\hline Criticism-Other (C-O) & 2.12 & 3.18 & $0-10$ \\
\hline $\begin{array}{l}\text { Positive Command } \\
\text { (COM-P) }\end{array}$ & 4.44 & 5.10 & $0-16$ \\
\hline $\begin{array}{l}\text { Negative Command } \\
(\mathrm{COM}-\mathrm{N})\end{array}$ & 1.24 & 2.44 & $0-11$ \\
\hline Question (QUE) & 77.08 & 35.18 & $15-150$ \\
\hline Listen (LI) & 44.16 & 30.23 & $1-112$ \\
\hline Ignore (IG) & 0 & 0 & 0 \\
\hline Reassurance-Ask (R-A) & 1.4 & 2.5 & $0-11$ \\
\hline Reassurance-Give (R-G) & 16.72 & 11.76 & $1-49$ \\
\hline Verbal Interruption (V-I) & 3.68 & 3.42 & $0-14$ \\
\hline $\begin{array}{l}\text { Descriptive Statement- } \\
\text { Task Related (DS-T) }\end{array}$ & 67.64 & 23.07 & $27-110$ \\
\hline $\begin{array}{l}\text { Off Task Verbal } \\
\text { Statement (OT-V) }\end{array}$ & 10.56 & 9.70 & $0-36$ \\
\hline
\end{tabular}

Note. $\mathrm{N}=25$; Values rounded to two decimals places 
Table 4

Correlations of Measures and Behavioral Observations

\begin{tabular}{|c|c|c|c|c|c|c|c|c|c|c|c|}
\hline & 1 & 2 & 3 & 4 & 5 & 6 & 7 & 8 & 9 & 10 & 11 \\
\hline 1. PBI-C-M: Care & & & & & & & & & & & \\
\hline 2. PBI-C-M: & -.36 & & & & & & & & & & \\
\hline Overprotection & & & & & & & & & & & \\
\hline 3. PBI-C-F: Care & $.62 * *$ & -.16 & & & & & & & & & \\
\hline 4. PBI-C-F: & -.17 & $.83 * *$ & -.33 & & & & & & & & \\
\hline Overprotection & & & & & & & & & & & \\
\hline 5. SPAI-C & -.06 & .23 & -.04 & .22 & & & & & & & \\
\hline 6. SPAI & .17 & -.11 & $.53 * *$ & -.38 & .17 & & & & & & \\
\hline 7. Parent COM-P & .03 & $.49 *$ & -.30 & $.66^{* *}$ & -.09 & -.19 & & & & & \\
\hline 8. Parent COM-N & .13 & $.40 *$ & $-.41 *$ & $.66^{* *}$ & -.07 & -.38 & $.77 * *$ & & & & \\
\hline 9. Parent C-O & .04 & .30 & -.30 & $.55^{* *}$ & -.03 & -.29 & $.71 * *$ & $.59 * *$ & & & \\
\hline 10. Parent VI & .14 & -.11 & .24 & -.18 & .09 & .14 & -.01 & -.21 & .21 & & \\
\hline 11. Parent $\mathrm{P}-\mathrm{O}$ & .15 & -.04 & .33 & -.03 & -.16 & -.31 & -.02 & -.14 & .10 & .26 & \\
\hline 12. Parent R-G & .10 & -.17 & $.49 *$ & -.31 & -.26 & .13 & -.35 & -.37 & -.31 & .33 & $.43^{*}$ \\
\hline
\end{tabular}

Note. * Significance level at .05; ** Significance level at .01; All values rounded to two decimal places 